\title{
Forsythia Flower as Natural Photosensitizer for Dye-sensitized Solar Cells
}

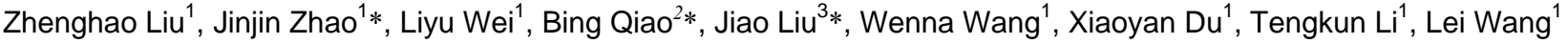 \\ 1School of Materials Science and Engineering, The Key Laboratory for Health Monitoring and Control of Large Structures, Shijiazhuang \\ Tiedao University, 17 Northeast, Second Inner Ring, Shijiazhuang, 050043, China \\ ${ }^{2}$ First Medical Oncology, Han Gang Hospital,188 Nonglin Road, Handan,056001, China \\ 3TCM Pharmacology Laboratory, Hebei Traditional Chinese Medicial College, Shijiazhuang 050200, China
}

\begin{abstract}
Pigments of Forsythia flowers were facilely extracted. Ultraviolet-visible (UV-Vis) absorption spectra of nanocrystal $\mathrm{TiO}_{2}$ film sensitized by Forsythia dyes, and photoelectric property of natural dye-sensitized solar cells (DSSCs) confirmed that the strong capacity of Forsythia visible light absorption, and the short-circuit current density and the photoelectric conversion efficiency of forsythia DSSC is $2.07 \mathrm{~mA} / \mathrm{cm}^{2}$ and $0.79 \%$, respectively, attributed by energy level well matching of forsythia dyes excited states with the $\mathrm{TiO}_{2}$ conduction band energy level.
\end{abstract}

\section{Introduction}

With increasing global energy consumption and environmental issues, the fabrication of low cost and high efficiency photovoltaic cells has attracted intense research interest in recent years, ${ }^{[1 \sim 3]}$ Since Grätzel developed dye-sensitized solar cells (DSSCs), a new type of solar cells ${ }^{[1]}$ in 1991. DSSCs are composed of the porous semiconductor electrode absorbed dye, the counter electrode and the electrolyte. The photoanode is prepared by adsorbing a dye into a porous $\mathrm{TiO}_{2}$ layer. By this approach, the dye enables the generation of electricity with visible light, extending the semiconductor's performance to collect photons at lower energy. ${ }^{[4]}$ DSSCs usually employ ruthenium(II) polypyridinic complexes as sensitizers of wide band gap semiconductors, although the energy conversion can also be achieved by natural dyes. But those synthetic dyes are expensive and complicated Purification. Alternatively, natural dyes can be used for the same purpose with an acceptable efficiency. ${ }^{[5-12]}$ Recent literature indicates that DSSC with anthocyanin has shown better performance than the DSSC using chlorophyll dye. The DSSC with the dye mixture exhibits better performance than individual dye. ${ }^{[13]}$ Here, DSSCs were prepared using natural dyes extracted from Forsythia as sensitizers. We firstly assembled forsythia as a sensitizer into solar cells, studied the performance of forsythia sensitized photovoltaic solar cells and the stability of device performance.

\section{Experimental Section}

\subsection{Chemicals}

Titanium tetrachloride (99.5\%), Ethanol (98\%), Nitric acid $(65 \%)$ were purchased from Sinopharm Chemical Reagent Co., Ltd; F127 was purchased from SigmaAldrich, Inc. Polyethylene glycol (PEG; 20000 in molecularweight) was purchased from J\&K. The sensitizer N719 (Cis-di(thiocyanato)-N, N-bis(2, 2' bipyridyl-4,4' - dicarboxylate)- $\mathrm{Ru}(\mathrm{II})$ bis-tetrabuty lammonium), electrolyte, surlyn film were purchased from Yingkou Opvtech New Energy Co., Ltd.

\subsection{Synthesis of the $\mathrm{TiO}_{2}$ film and fabrication of Forsythia -Dye Sensitized Solar Cells (FDSC)}

\subsubsection{Synthesis of $\mathrm{TiO}_{2}$ nanoparticles}

$\mathrm{TiO}_{2}$ nanoparticles were synthesized as the following method. $2.97 \mathrm{~g} \mathrm{F127}$ was firstly dissolved in $36.88 \mathrm{~g}$ ethanol at $40^{\circ} \mathrm{C}$ for 30 minutes to form a clear solution. Then $3.4 \mathrm{~g} \mathrm{TiCl}_{4}$ was added to the obtained solution. The precursor solutions were placed into a Teflon-lined stainless steel autoclave (100 mL in capacity) after stirring $8 \mathrm{~h}$ under $40^{\circ} \mathrm{C}$. The autoclave was placed in an oven at $160^{\circ} \mathrm{C}$ for $16 \mathrm{~h}$. Subsequently, the products were filtered, washed and dried at $80^{\circ} \mathrm{C}$. Finally, the powders were sintered at $610^{\circ} \mathrm{C}$ for 10 minutes after being kept at $300^{\circ} \mathrm{C}$ for 90 minutes and $500^{\circ} \mathrm{C}$ for 240 minutes. During the whole process, the heating rate was kept at a constant of $2^{\circ} \mathrm{C} / \mathrm{min}$. After sintering, the products were dispersed using deionized water and nitric acid (65\%) until the $\mathrm{pH}$ of the solution reached to about $2 \cdot{ }^{[14]}$ Then the mixture solution was vigorous stirred at $80^{\circ} \mathrm{C}$ for 8 hours to obtain $\mathrm{TiO}_{2}$ nanoparticles.

\subsubsection{Preparation of Mesoporous $\mathrm{TiO}_{2}$ films}

FTO conductive glass sheets $\left(\mathrm{SnO}_{2}: \mathrm{F}\right.$ coated glass, FTO, sheet resistance: $8 \mathrm{ohm} / \mathrm{sq}$ ) were first cleaned in a detergent solution using an ultrasonic bath for $15 \sim 30 \mathrm{~min}$, rinsed with water, ethanol, acetone and then dried with nitrogen. The mesoporous $\mathrm{TiO}_{2}$ films with a thickness of $8 \sim 15 \mu \mathrm{m}$ were prepared by the doctor-blade method. First of all, the $\mathrm{TiO}_{2}$ paste was made with the $\mathrm{TiO}_{2}$ nanoparticles synthesized in section 2.1. Briefly, $0.8 \mathrm{~g}$ $\mathrm{TiO}_{2}$ was added in a mixed solution of ethanol/deionized water (3:1) and treated using ultrasonic for 30 minutes after the addition of PEG aqueous which acted as the pore-forming material. Then they were grinded into ropiness in agate mortar. A mask, with a window encompassed by $3 \mathrm{M}$ scotch tape, was used to define the 
$5 \mathrm{~mm} \times 5 \mathrm{~mm}$ area which was used to spread the paste dropped one edge of the window with a glass slide on the FTO conductive glass. Subsequently, the as-prepared $\mathrm{TiO}_{2}$ films were sintered in air with the heating rate of $2^{\circ} \mathrm{C} / \mathrm{min}$ to $300^{\circ} \mathrm{C}$ for $30 \mathrm{~min}, 500^{\circ} \mathrm{C}$ for $60 \mathrm{~min}$.

\subsubsection{Preparation of natural dye sensitizers}

The natural dyes were prepared by the following steps: Forsythia flowers were washed with water and dried at $50{ }^{\circ} \mathrm{C}$ for $15 \mathrm{~min} .2 \mathrm{~g}$ fresh Forsythia flowers were crushed using a mortar and immersed in $10 \mathrm{ml}$ ethanol solution at room temperature in the dark for 3 hours, and then solid residues were filtrated out. The resulting filtrates were used as sensitizers.

\subsubsection{Preparation of Forsythia dye-sensitized solar cell}

The mesoporous $\mathrm{TiO}_{2}$ films were sensitized with Forsythia dye or N719 dye by direct adsorption. Firstly, the as-prepared $\mathrm{TiO}_{2}$ films were heated to $80{ }^{\circ} \mathrm{C}$ and immersed in the Forsythia dye and N719 ethanol solution

$(0.5 \mathrm{mM})$ for $24 \mathrm{~h}$, respectively. After rinsing the film in solution by ethanol and drying, the desired mesoporous $\mathrm{TiO}_{2}$ / Forsythia dye film and $\mathrm{TiO}_{2} / \mathrm{N} 719$ electrodes were obtained.

The photovoltaic cells were assembled with the mesoporous $\mathrm{TiO}_{2} /$ Forsythia dye film or $\mathrm{TiO}_{2} / \mathrm{N} 719$ photoelectrode, Pt coated counter electrode, and $60 \mu \mathrm{m}$ thick sealing material (OPV-SN-60). Commercially available electrolyte of $\mathrm{I}_{3}^{-} / \mathrm{I}^{-}$was injected into the space between the photoelectrode and counter electrode.

\subsection{Characterization}

UV-Vis absorption spectras were recorded with a Shimadzu UV-2550 (300 - 600 nm: xenon lamp, $300 \mathrm{~W}$; 600 - $900 \mathrm{~nm}$ : tungsten-halogen lamp, $150 \mathrm{~W})$. The infrared spectra of functional groups on forsythia pigment analysis were taken on a Fourier transform infrared (FTIR) spectrometer (Nicolet 330, Thermo, USA). XRD patterns were obtained using D8 Advance (Germany) diffractometer with $\mathrm{Cu} \mathrm{K}$ a radiation $(40 \mathrm{kV}$ and $40 \mathrm{~mA}$ ) with the scanning rate of $4^{\circ} \mathrm{min}-1$ for wide angle test sincrement over the Bragg angle range of $20-90^{\circ}$. The $\mathrm{N}_{2}$ sorption measurements were performed using Micromeritics Tristar 3000 for mesoporosity and Micromeritics ASAP 2020 porosimeters and microposity at $77 \mathrm{~K}$, respectively. The mesoporous specific surface area and the pore size distribution were calculated using the Brunauer - Emmett - Teller (BET) methods. SEM (Scanning Electron Microscopy) analysis was performed on a Hitachi-S-4800 electron microscope. The photocurrent-voltage $(\mathrm{J}-\mathrm{V})$ characteristics of the solar cells were measured using a Keithley 2400 Source under illumination of a simulated sunlight (AM1.5, 100 $\mathrm{mW} / \mathrm{cm}^{2}$ ) provided by a solar simulator (Newport 69907) with an AM 1.5 filter. Light intensity was adjusted with an NREL-calibrated Si solar cell with a KG-2 filter for approximating 1 sun light intensity. The incident photonto-current efficiency (IPCE) was measured in DC mode with a $1 / 4 \mathrm{~m}$ double monochromator (Crowntech DK242), a multi-meter (Keithley 2000), and two light sources depending on the wavelength range required $(300-600$ $\mathrm{nm}$ : xenon lamp, $300 \mathrm{~W}$; 600 - $900 \mathrm{~nm}$ : tungsten-halogen lamp, $150 \mathrm{~W})$. The monochromatic light intensity for IPCE efficiency was calibrated with a reference silicon photodiode.

\section{Results and discussion}

\subsection{Structural characterization}

SEM and TEM image of $\mathrm{TiO}_{2}$ nanoparticles were shown in Fig.1. It shows that the diameter of the prepared $\mathrm{TiO}_{2}$ particles was about $20-50 \mathrm{~nm}$. Fig. 2 shows the XRD patterns of the $\mathrm{TiO}_{2}$ nanoparticles. The $\mathrm{TiO}_{2}$ particles

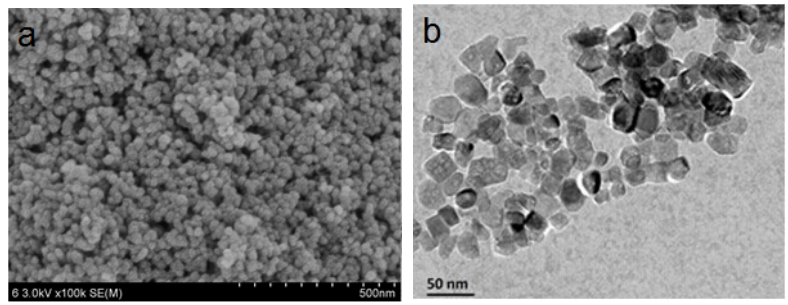

Fig.1 SEM and TEM image of $\mathrm{TiO}_{2}$ nanoparticles

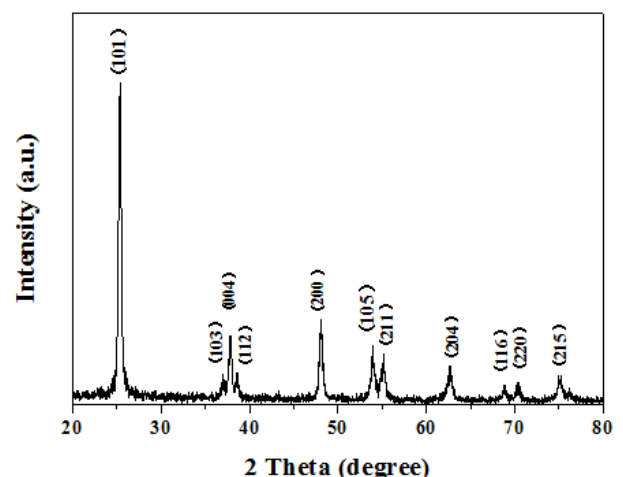

Fig.2 XRD (PDF:73-1764) patterns of $\mathrm{TiO}_{2}$ nanoparticles

exhibited diffraction peaks at $2 \theta$ values of $25.51^{\circ}$, $37.08^{\circ}, 37.89^{\circ}, 38.714^{\circ}, 48.18^{\circ}, 54.05^{\circ}, 55.403^{\circ}$, $62.96^{\circ}, 69.01^{\circ}, 72.45^{\circ}, 75.29^{\circ}$, corresponding to the (101), (103), (004), (112), (200), (105), (211), (204), (116), (220), (215) crystal planes of anatase $\mathrm{TiO}_{2}$ (I4 1 /amd, JCPDS 73-1764). The observed XRD results are well matched with already reported literature. ${ }^{[18]}$

Nitrogen sorption isotherms of the $\mathrm{TiO}_{2}$ nanoparticles and the corresponding pore size distribution curve (inset) are shown in Fig.3. The isotherms of $\mathrm{TiO}_{2}$ nanoparticles exhibit a $\mathrm{TiO}_{2}$ nanoparticles has type-H1 hysteresis loop, characteristic of mesoporous materials, with clear adsorption and desorption jumps at 0.6 and 0.9 . The specific surface area of $45.24 \mathrm{~m}^{2} / \mathrm{g}$ and pore volume of $0.16 \mathrm{~cm}^{3} / \mathrm{g}$, an average pore diameter of $10.4 \mathrm{~nm}$, which are enough for the high capacity enrichment of Forsythia flower dye. 


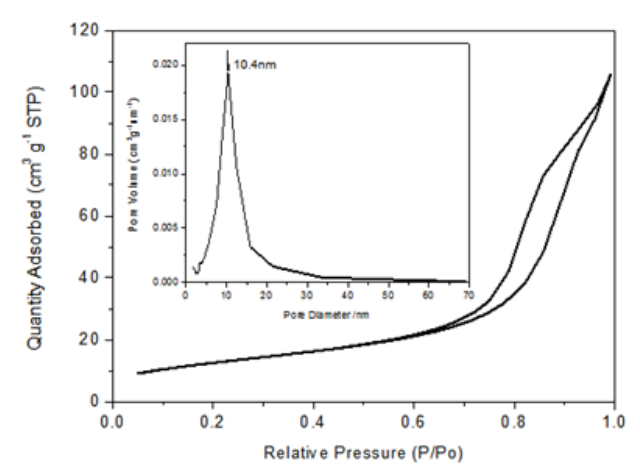

Fig. $3 \mathrm{~N}_{2}$ adsorption-desorption isotherms and the corresponding pore diameter distribution curves of $\mathrm{TiO}_{2}$ nanoparticles

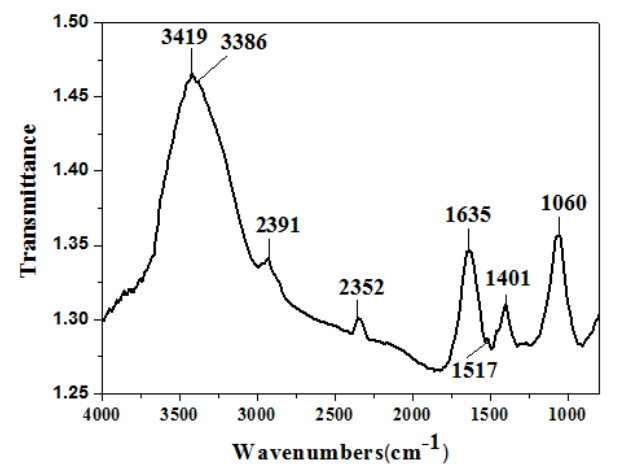

Fig.4 the FT-IR absorption spectrum of forsythia flower pigment

The FT-IR absorption spectrum of forsythia flower pigment was shown in Fig.4. It is noted that pigment's molecular structure found in forsythia flowers in accordance with the report ${ }^{[19]}$. Fig 5 showed molecular formula of forsythia phillyrin and forsythiaside glycosides.

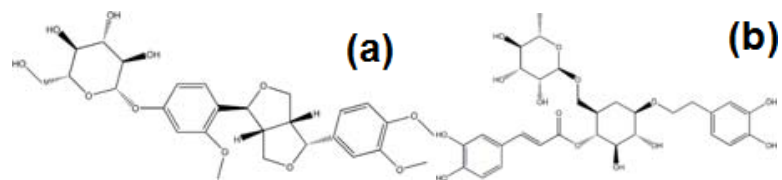

Fig. 5 the main components of forsythia flower pigment: molecular formula of forsythia phillyrin (a) and forsythiaside glycosides (b)

Fig.6 shows the UV-vis absorption spectra of nanocrystalline $\mathrm{TiO}_{2}$ film (black) and nanocrystalline $\mathrm{TiO}_{2}$ film sensitized by Forsythia (red). The absorption onset for $\mathrm{TiO}_{2}$ is approximately $450 \mathrm{~nm}$, while the absorption onset of sensitized $\mathrm{TiO}_{2}$ film is about $665 \mathrm{~nm}$. The difference in the absorption characteristics is due to nanocrystal $\mathrm{TiO}_{2}$ film sensitized by Forsythia. Fig.7 reports a plot of $(A h v)^{2}$ versus $h v$ (A=absorbance, $h=$ Planck's constant, and $v=$ frequency $)$, from which it is possible to extrapolate the slope near the absorption edge and extract the band gap energy. ${ }^{[15]}$ The fits yielded $1.81 \mathrm{eV}$ for $\mathrm{TiO}_{2} @$ Fo-dye, which is lower than the band gap value of $\mathrm{TiO}_{2}(\mathrm{Eg}=3.2 \mathrm{eV})$, due to the density of state of $\mathrm{TiO}_{2} /$ Fo-dye contributed by the surface states of Fodye.

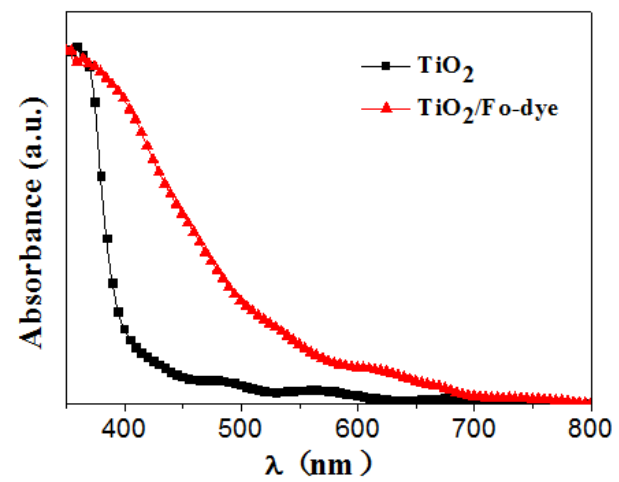

Fig.6 UV-vis absorption spectra of nanocrystalline $\mathrm{TiO}_{2}$ film and nanocrystalline $\mathrm{TiO}_{2}$ film sensitized by Forsythia

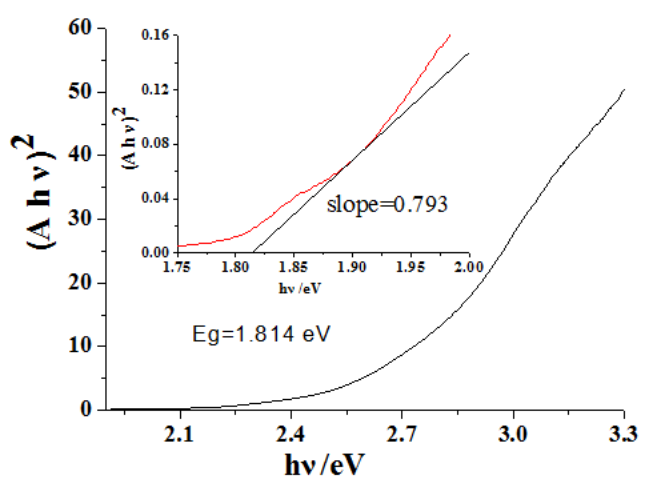

Fig.7 Plots of $(A h v)^{2}$ against the photon energy $(h v)$ for $\mathrm{TiO}_{2} /$ Fo-dye

As observed in Fig.8, it shows the intramolecular charge transfer (ICT) from donor to acceptor/anchoring group. the pattern of the HOMOs and LUMOs are beneficial for the photoexcitation electrons injection. The dye has considerable contribution to the LUMOs which could lead to a strong electronic coupling with $\mathrm{TiO}_{2}$ surface and thus improved the electron injection efficiency, and subsequently enhance the short-circuit current density Jsc. ${ }^{[16]}$

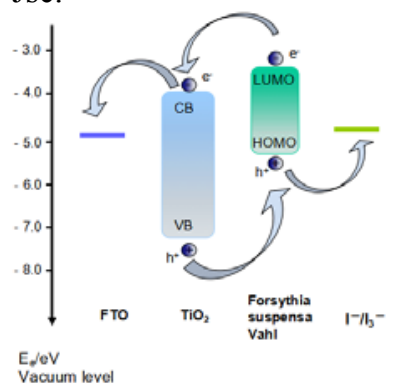

Fig.8 A schematic showing the relative band energy levels for charge transfer in the $\mathrm{FTO} / \mathrm{TiO}_{2} /$ Forsythia electrolyte.

The photocurrent-voltage curves of the DSSCs based on Forsythia in Fig.9a was measured under light irradiation with intensity of $100 \mathrm{~mW} / \mathrm{cm}^{2}$. The photovoltaic parameters of DSSCs such as $\mathrm{J}_{\mathrm{SC}}, \mathrm{V}_{\mathrm{OC}}, \mathrm{FF}$ and PCE are listed in Fig.9a. The PCE of DSCs based on Forsythia reaches $0.79 \%$, which is higher than that of Rosella ( $\mathrm{PCE}=0.37 \%)$, Blue pea $(\mathrm{PCE}=0.05 \%)$ Mixed rosella-blue pea $(\mathrm{PCE}=0.15 \%) .{ }^{[17]}$ Fig. $9 \mathrm{~b}$ shows that the IPCE curves respond from $400 \mathrm{~nm}$ to $600 \mathrm{~nm}$, which has 
a greatest IPCE performance in general, with the maximum at $440 \mathrm{~nm}$.
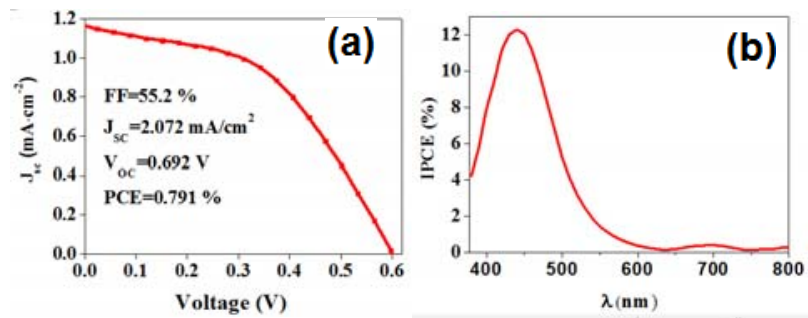

Fig.9 (a) photocurrent density-voltage (J-V) and (b) Incidentphoton-to-current conversion efficiency (IPCE) photocurrent density-voltage (J-V) curves of the DSCs

For the stability of forsythia dyes device, we measured the photocurrent-voltage curves of the DSSCs based on Forsythia under light irradiation with intensity of 100 $\mathrm{mW} / \mathrm{cm}^{2} 130$ times. As observed in Fig.10 (a), the efficiency is maintained at between $0.61 \%-0.71 \%$ which indicating that the pigment from the forsythia as a sensitizer is stable. Fig.10 (b) shows the UV-vis absorption spectra of dyes storaged in different temperature. It was found that the absorption peak of dyes storaged in different temperature are the same, which indicates that the dye is stability to temperature and has good stability.

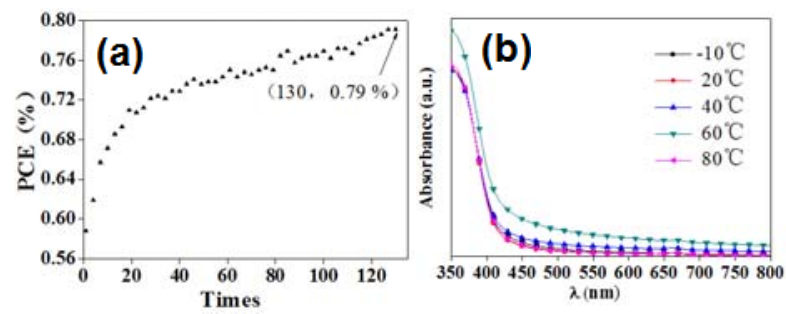

Fig.10 (a) relation curve of Forsythia's photoelectric conversion efficiency and the test number of times; (b) UV-vis absorption spectra of dyes treated in different temperature

\section{Conclusions}

Ultraviolet-visible (UV-vis) absorption spectra of forsythia dyes, and photoelectric performance of DSSCs showed that the visible absorption ability, the shortcircuit current and the photoelectric conversion efficiency of forsythia DSSC, and forsythia dyes excited states of LUMO and HOMO energy levels with the $\mathrm{TiO}_{2}$ conduction band energy level and electrolyte oxidation reduction. The photoelectric conversion efficiency of Forsythia DSSC reached $0.79 \%$. Natural dyes can be used for the same purpose with a good efficiency, and moreover natural dye performance is stable, low-cost, environment-friendly.

The authors thank the financial support from China Scholarship Council, The project of Shijiazhuang Tiedao University for excellent young teachers, Hebei Provincial Key Laboratory of Traffic Engineering materials, Hebei Key Discipline Construction Project. College students' innovative entrepreneurial training project of China

\section{References}

[1] M. Grätzel, Acc. Chem. Res. 42, 1788 (2009).

[2] T. T. Wang, P. Raghunath, Y. F. Lu, Y. C. Liu, C. H. Chiou, M. C. Lin, Chem. Phys. Lett. 510, 126 (2011).

[3] Q. Wang, Nature, 494, 403 (2013).

[4] G. Calogero, G. Di Marco, Sol. Energy Mater. Sol. Cells, 92, 1341 (2008).

[5] K. Tennakone, G. R. R. A. Kumara, A. R. Kumarasinghe, P. M. Sirimanne, K.G.U. Wijayantha, J. Photochem. Photobiol. A., 94, 217 (1996).

[6] S. Hao, J. Wu, Y. Huang, J. Lin, Sol. Energy, 80, 209 (2006).

[7] Y. Amao, T. Komori, Biosensors Bioelectron. 19, 843 (2004).

[8] A. S. Polo, N. Y. Iha, Sol. Energy Mater. Sol. Cells, 90, 1936 (2006).

[9] C. G. Garcia, A. S. Polo, N. Y. Iha, J. Photochem. Photobiol A., 160, 87 (2003).

[10] G. P. Smestad, Sol. Energy Mater. Sol. Cells, 55, 157 (1998).

[11] G. R. A. Kumara, S. Kanebo, M. Okuya, B. Onwona-Agyeman, A. Konno, K. Tennakone, Sol. Energy Mater. Sol. Cells, 90, 1220 (2006).

[12] N.J. Cherepy, G.P. Smestad, M. Gra“ tzel, J.Z. Zang, J. Phys. Chem. B101 (1997) 9342.

[13] M. M. Noor, M. H. Buraidah, M. A. Gareem, S. R. Majid, A. K. Arof, Electrochimica Acta,121, 159 (2014).

[14] A. B. F. Martinson, T. W. Hamann, M. J. Pellin and J. T. Hupp, Chemistry - A European Journal, 14, 4458 (2008).

[15] M. Shalom, J. Albero, Z. Tachan, E. MartínezFerrero, A. Zaban, E. Palomares, J. Phys. Chem. Lett., 1, 1134 (2010).

[16] A. Fitri, A. T. Benjelloun, M. Benzakour, M. Mcharfi, M. Hamidi, M. Bouachrine, Spectrochimica Acta Part A-Molecular and Biomolecular Spectroscopy, 132, 232 (2014).

[17] K. Wongcharee, V. Meeyoo, S. Chavadej, Sol. Energy Mater. Sol. Cells, 91, 566 (2006).

[18] J. Zhao, J. Zhang, W. Wang, P. Wang, F. Li, D. Ren, H. Si, X. Sun, F. Ji, Y. Hao, Dalton Trans. 43, 16588 (2014).

[19]B. Luo, J. Z. Zhang, Chinese Joumal of Experimental Traditional Medical Fomulae 19, 143-146 (2013). 